\title{
Thermal Sampling and Compensation Phenomena of PVVH/ZnO Nanocomposite Polymer Using TSDC Technique
}

\author{
Moustafa Tawfik Ahmed*, Maysa Ismail Abd-Elhamid, Afaf Sarhan, Aya Hassan \\ Physics Department, Faculty of Science, Mansoura University, Mansoura, Egypt \\ Email address: \\ moustf_1@yahoo.com (M. T. Ahmed) \\ ${ }^{*}$ Corresponding author \\ To cite this article: \\ Moustafa Tawfik Ahmed, Maysa Ismail Abd-Elhamid, Afaf Sarhan, Aya Hassan. Thermal Sampling and Compensation Phenomena of \\ PVVH/ZnO Nanocomposite Polymer Using TSDC Technique. Modern Chemistrys. Vol. 5, No. 4, 2017, pp. 60-69. \\ doi: $10.11648 /$ j.mc.20170504.12
}

Received: May 16, 2017; Accepted: July 4, 2017; Published: August 10, 2017

\begin{abstract}
Thermo-electrets of poly (vinyl chloride-co-vinyl acetate-co-2 hydroxy propyl acrylate) PVVH and its nanocomposite $\mathrm{PVVH} / \mathrm{ZnO}$ were prepared using the thermal poling method. Thermally stimulated depolarization current TSDC technique used to study the alpha relaxation of the samples. The global spectra of the nanocomposites revealed that $\mathrm{ZnO}$ nanoparticles are completely compatible with the polymer matrix. The activation energy was calculated and found to be in the range of 0.69-1.25 eV. TS technique was used to resolve the complex TSDC behavior and thermodynamic parameters were obtained from Eyring relationship which verified the linear relation between the activation enthalpy $\Delta \mathrm{H}$ and the activation entropy $\Delta \mathrm{S}$. The compensation phenomena had been studied and the degree of disorder DOD of all samples has been calculated and results values in the range 15 to $35.24 \mathrm{Cal}_{\text {degree }}{ }^{-1}$.
\end{abstract}

Keywords: Nanocomposites, TSDC, Thermal Sampling, Enthalpy, Entropy, Activation Free Energy, Compensation, DOD

\section{Introduction}

Polymer nanocomposites have gained a great attention in recent years due to their mechanical and barrier properties, especially at very low filler content, it has a wide field of applications such as super capacitors, solar cells, sensors and lithium ion batteries [1]. One of the most useful and very high sensitive techniques which used to study the dielectric relaxation of materials is thermal stimulated depolarization current TSDC technique. TSDC was used to study and quantify the defects (trap charges, dipoles or oxygen vacancies) which exist in the dielectric materials [2], the accumulations of charges in polycrystalline [3], also to evaluate the influence of dipole content on the relaxation strength and the thermal stability of the system [4]. Generally, TSDC technique is a dielectric technique in which the dynamic of the system is observed through the trend of the previously aligned structural dipoles to orientate at random as the mobility of the system increase during the continuous heating from temperatures far below $T_{g}$ [5]. Poly (vinyl chloride-co- vinyl acetate-co-2-hydroxypropyl acrylate) PVVH is a linear terpolymer which is characterized by its flexibility and the structure is highly sensitive to the variation of temperature [6] is selected for this study. Thermal sampling technique (TS) has been applied to polymers, showing the ability to isolate quasi-elementary process of the complex spectra, enabling a complete characterization of the corresponding distribution of characteristic times [7]. By using Arrhenius equation, it is very easy to study the activation energy and relaxation time of the polymer [8]. Also by using Eyring relation, it is easy to study thermodynamic parameters such as Gibb's free energy, enthalpy and entropy which show a linear relationship between the enthalpy and entropy [9-10], it also allows to study the compensation phenomena which characterized by compensation point (is indicative of cooperative molecular movements and that $T_{c}$ is the temperature at which all the relaxations involved in the process occur with the same relaxation time) [11], which is correlated to the physical properties of the material.

The aim of this paper is to study the TSDC spectra of PVVH with doping $\mathrm{ZnO}$ nanoparticles, also the TS behavior of the nanocomposite with different concentrations. The 
thermodynamic parameters, compensation phenomena, the degree of disorder and thermal expansion of samples were calculated. The activation energy and relaxation time were calculated from TSDC and TS spectra.

\section{Experimental}

\subsection{Materials}

Poly (vinyl chloride - co vinyl acetate - co 2hydroxypropyl acrylate) (PVVH) (Aldrich chemical company, USA), Dimethyl formamide (El Nasr pharmaceutical chemical co. Egypt) and Acetic Acid 96\% (El Nasr pharmaceutical chemical co. Egypt), Zinc sulphate hepta-hydrate (Alfa Aesar, Germany), Sodium Hydroxide (El Nasr pharmaceutical chemical co. Egypt) and Deionized water is used for preparing $\mathrm{ZnO}$ nanoparticles.

\subsection{Methods}

\subsubsection{Preparation of PVVH/ZnO Nanocomposites Polymer Films}

PVVH was dissolved in $20 \mathrm{ml}$ DMF under continuous stir at $323 \mathrm{~K}$ until completely dissolved. $\mathrm{ZnO}$ nanoparticles powder (with different concentrations) is dissolved in $10 \mathrm{ml}$ DMF with $0.5 \mathrm{ml}$ acetic acid as an initiator, stir until completely dissolved, then it sonicated for 20 minutes. The $\mathrm{ZnO}$ solution was added to PVVH solution drop by drop, then stir and sonicated for 1 hour. The resultant solution of $\mathrm{PVVH} / \mathrm{ZnO}$ is poured into a glass petri dish in the oven at $333 \mathrm{~K}$ for two days. Films are ready with thickness ranged from 30 to $60 \mu \mathrm{m}$, which measured by digital micrometer Mitutoyo no 293-521-30 Japan. Carbon paste KontactChemie, Germany was used as a conducting electrode.

\subsubsection{TSDC Instrument}

A home-made cell was used to investigate the global TSDC spectra through temperature range 300-400 K. Parallel plate electrodes were used, with the upper plate springloaded to maintain electrical contact during thermal cycling. To obtain a global TSDC spectrum, the samples were polarized by a static electric field of $3 \times 10^{6} \mathrm{~V} / \mathrm{m}$ at the polarizing temperature $T_{p}$ down to the freezing temperature, with cooling to freeze in dipole orientation. When samples are short-circuited, the depolarization current due to segmental orientation was measured as the temperature increased. The current was measured with a Keithley electrometer $610 \mathrm{C}$ at a constant heating rate $3 \mathrm{~K} / \mathrm{min}$. The temperature was measured with a temperature controller unit Digi-sence, 2186-25A, Cole-Parmer instrument Co, USA.

Spectra were obtained by applying the polarizing field for 10 min over a narrow range of temperature from $T_{p}$ to $T_{p}-5 K$ and then depolarizing for $10 \mathrm{~min}$ at temperature $\mathrm{T}_{\mathrm{d}}=\mathrm{T}_{\mathrm{p}}-5 \mathrm{~K}$ with the field off. The samples were quenched to the lower desired temperature with the field off. The depolarization spectrum due to a narrow distribution of relaxations was then measured upon reheating at $3 \mathrm{~K} / \mathrm{min}$. By applying the TS technique at different polarizing temperature windows $T_{p}-T_{d}$
$=5 \mathrm{~K}$, sets of depolarization curves were obtained for every polarization temperature which are subsets of that obtained from the global TSDC spectra. The signal for this TS spectrum is the result of the reorientation of the narrow packet relaxations which were excited over the $5 \mathrm{~K}$ temperature window around $T_{p}$. Details of the experimental arrangement and measuring techniques.

\section{Results and Discussion}

Figure 1, shows the global TSDC spectra of pure PVVH and $\mathrm{PVVH} / \mathrm{ZnO}$ nanocomposite with different concentrations under the same conditions $\mathrm{T}_{\mathrm{p}}=353 \mathrm{~K}, \mathrm{E}_{\mathrm{p}}=3 \times 10^{6} \mathrm{~V} / \mathrm{m}, \mathrm{t}_{\mathrm{p}}=10$ min with constant heating rate $3 \mathrm{~K} / \mathrm{min}$. The $\mathrm{T}_{\mathrm{p}}$ of $353 \mathrm{~K}$ was selected near to the glass transition temperature to avoid space charge mechanism or degradation effects. The TSDC for all samples show the same behavior with a single characteristic peak, which covering the glass transition temperature range (333-349) $\mathrm{K}$, is assigned to the $\alpha$ relaxation of PVVH chains in an interfacial layer close to $\mathrm{ZnO}$ nanoparticles [12]. From TSDC spectra, it is clear that the glass transition temperature increases with increasing the concentration of nanoparticle in the polymeric matrix which is corresponding to the increase of the amorphous region of PVVH matrix [13]. The current of TSDC for $\mathrm{PVVH} / \mathrm{ZnO}$ nanocomposites increases with increasing $\mathrm{ZnO}$ concentration up to $1 \%$ which can indicate the increase of dipole-dipole interaction [14].

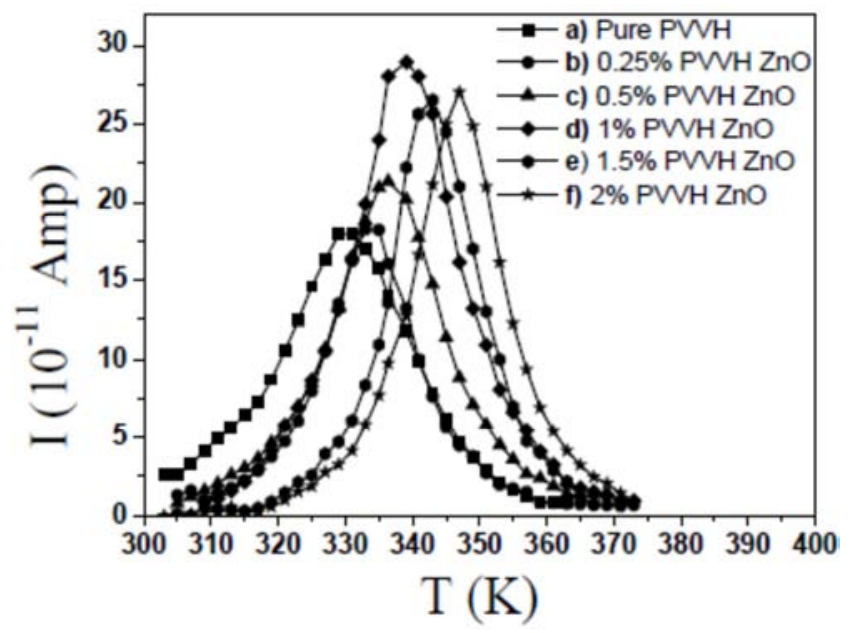

Figure 1. Global TSDC spectra of pure PVVH and PVVH/ZnO nanocomposite with different $\mathrm{ZnO}$ nanoparticle concentrations under constant conditions $E_{p}=3 \times 10^{6} \mathrm{~V} / \mathrm{m}, T_{p}=353 \mathrm{~K}, t_{p}=10$ min using carbon paste as an electrode.

The activation energy and relaxation time were calculated from the initial rise part of the spectra by using the Arrhenius equation [8]:

$$
\mathrm{I}=\mathrm{I}_{\mathrm{o}} \exp \left(\mathrm{E}_{\mathrm{a}} / \mathrm{kT}\right)
$$

Where $\mathrm{T}$ is the absolute temperature, $\mathrm{E}_{\mathrm{a}}$ is the activation energy and $\mathrm{k}$ is Boltzmann constant. 


$$
\tau(\mathrm{T})=\tau_{0} \exp \left(\mathrm{E}_{\mathrm{a}} / \mathrm{kT}\right)
$$

Where, $\tau_{\mathrm{o}}$ is the pre-exponential factor.

The calculated activation energies were found to be in the range of $0.69-1.25 \mathrm{eV}$ results from the degree of cooperative
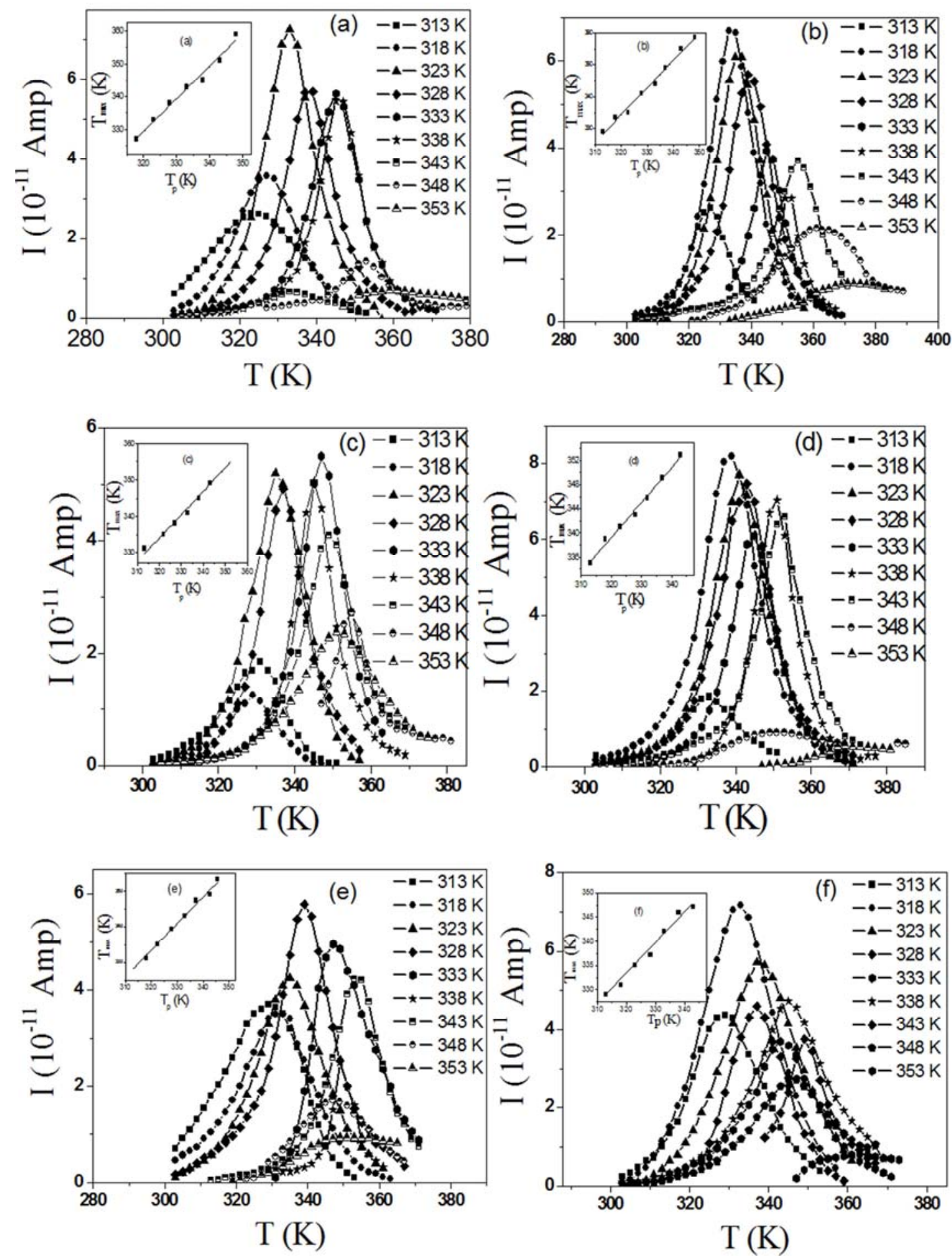
temperature [5]. The relaxation times of all samples with different concentrations were found to be in the range of 10 17 to 10-9 for dipole segmental motion, the molecular parameters are tabulated in table 1 .

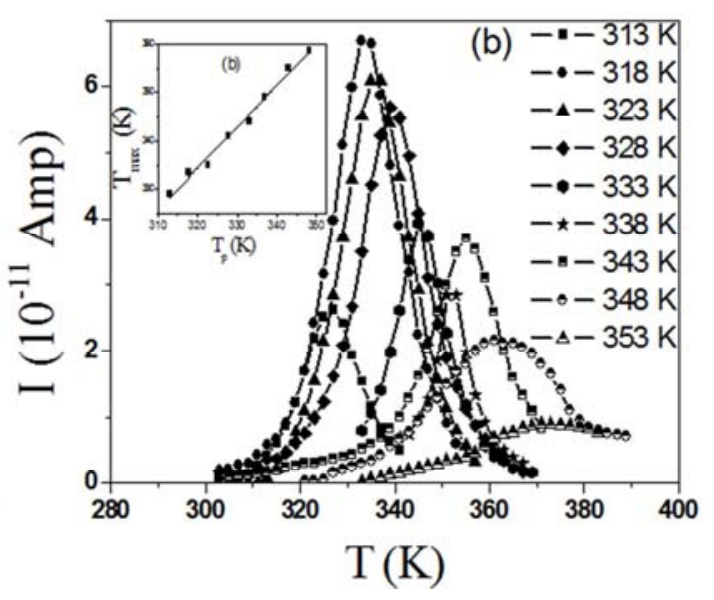

Figure 2. Typical TS spectra of (a) pure PVVH and PVVH/ZnO nanocomposites with different ZnO nanoparticle concentrations (b: $0.25 \%$, c: 0.5\%, d: $1 \%$, e: $1.5 \%$ and $f: 2 \%$.

In order to study the resolving of the complex spectrum of TSDC to its elementary process, TS technique has been studied for pure PVVH and its nanocomposite with different

nature in the molecular motion at the glass transition 
in figure 2. Each TS spectrum results as a set of peaks, which is characterized by a single peak at different maximum positions depending on the poling temperature. The maximum temperature increases linearly with the poling field, the inset figure 2, the slope of this line is unity, which agrees with the theoretical prediction of continuous distribution [15]. The molecular parameters associated with the dipolar relaxation process of all samples, such as activation energy and pre-exponential factor have been calculated by using the initial rise method as listed in table 2 .

It is clear that the distribution of the activation energy and relaxation time are reversely and can be corresponding to the different relaxation modes in polymeric materials, the high values of the activation energy correspond to the strong intermolecular interaction at the glass transition temperature [16].

Table 1. The molecular parameters of $\mathrm{PVVH} / \mathrm{ZnO}$ nanocomposite.

\begin{tabular}{|c|c|c|c|c|}
\hline Samples & Maximum current $\left(10^{-11}\right.$ Amber $)$ & Maximum temperature (K) & Activation energy (eV) & Relaxation time (sec) \\
\hline Pure PVVH & 18 & 331 & 0.697394 & $6.52 \mathrm{E}-09$ \\
\hline $0.25 \% \mathrm{PVVH} / \mathrm{ZnO}$ & 19 & 333 & 1.196031 & $1.27 \mathrm{E}-16$ \\
\hline $0.5 \% \mathrm{PVVH} / \mathrm{ZnO}$ & 21 & 335 & 0.850167 & $3.69 \mathrm{E}-11$ \\
\hline $1 \% \mathrm{PVVH} / \mathrm{ZnO}$ & 28 & 339 & 0.897312 & $1.01 \mathrm{E}-11$ \\
\hline $1.5 \% \mathrm{PVVH} / \mathrm{ZnO}$ & 26 & 343 & 1.250054 & $6.96 \mathrm{E}-17$ \\
\hline $2 \% \mathrm{PVVH} / \mathrm{ZnO}$ & 26 & 349 & 1.234329 & $2.55 \mathrm{E}-16$ \\
\hline
\end{tabular}

Table 2. The molecular parameters of TS spectra for all samples.

\begin{tabular}{|c|c|c|c|c|}
\hline sample & Polar Window (K) & Maximum temperature (K) & Activation energy (eV) & Relaxation time (sec) \\
\hline \multirow{7}{*}{ Pure PVVH } & $313-308$ & 324 & 0.457 & $3.076 \mathrm{E}-05$ \\
\hline & $318-313$ & 327 & 0.848 & $1.882 \mathrm{E}-11$ \\
\hline & $323-318$ & 333 & 1.200 & $1.080 \mathrm{E}-16$ \\
\hline & $328-323$ & 338 & 1.443 & $4.170 \mathrm{E}-20$ \\
\hline & $333-328$ & 343 & 1.925 & $5.473 \mathrm{E}-27$ \\
\hline & $338-333$ & 345 & 1.607 & $4.321 \mathrm{E}-22$ \\
\hline & $343-338$ & 351 & 0.653 & $1.357 \mathrm{E}-07$ \\
\hline \multirow{7}{*}{$0.25 \% \mathrm{PVVH} / \mathrm{ZnO}$} & $313-308$ & 329 & 0.536 & $2.159 \mathrm{E}-06$ \\
\hline & $318-313$ & 333 & 1.347 & $5.805 \mathrm{E}-19$ \\
\hline & $323-318$ & 335 & 1.366 & $4.014 \mathrm{E}-19$ \\
\hline & $328-323$ & 341 & 0.632 & $1.469 \mathrm{E}-07$ \\
\hline & $333-328$ & 344 & 2.071 & $4.498 \mathrm{E}-29$ \\
\hline & $338-333$ & 349 & 3.317 & $7.926 \mathrm{E}-47$ \\
\hline & $343-338$ & 355 & 0.548 & $6.614 \mathrm{E}-06$ \\
\hline \multirow{7}{*}{$0.5 \% \mathrm{PVVH} / \mathrm{ZnO}$} & $313-308$ & 331 & 0.710 & 4.043E-09 \\
\hline & $318-313$ & 329 & 2.273 & $1.241 \mathrm{E}-33$ \\
\hline & $323-318$ & 335 & 0.951 & $9.934 \mathrm{E}-13$ \\
\hline & $328-323$ & 335 & 0.971 & $4.934 \mathrm{E}-13$ \\
\hline & $333-328$ & 341 & 1.559 & $1.164 \mathrm{E}-21$ \\
\hline & $338-333$ & 345 & 1.697 & $1.976 \mathrm{E}-23$ \\
\hline & $343-338$ & 349 & 1.206 & $6.789 \mathrm{E}-16$ \\
\hline \multirow{7}{*}{$1 \% \mathrm{PVVH} / \mathrm{ZnO}$} & $313-308$ & 335 & 0.273 & $5.470 \mathrm{E}-02$ \\
\hline & $318-313$ & 339 & 1.177 & $5.367 \mathrm{E}-16$ \\
\hline & $323-318$ & 341 & 1.173 & $7.777 \mathrm{E}-16$ \\
\hline & $328-323$ & 343 & 1.200 & $3.977 \mathrm{E}-16$ \\
\hline & $333-328$ & 345 & 1.260 & $6.461 \mathrm{E}-17$ \\
\hline & $338-333$ & 349 & 1.396 & $1.047 \mathrm{E}-18$ \\
\hline & $343-338$ & 353 & 1.225 & $5.710 \mathrm{E}-16$ \\
\hline \multirow{6}{*}{$1.5 \% \mathrm{PVVH} / \mathrm{ZnO}$} & $313-308$ & 329 & 0.547 & $1.409 \mathrm{E}-06$ \\
\hline & $318-313$ & 331 & 0.773 & $4.166 \mathrm{E}-10$ \\
\hline & $333-328$ & 343 & 2.426 & $1.877 \mathrm{E}-34$ \\
\hline & $338-333$ & 347 & 3.116 & $3.744 \mathrm{E}-44$ \\
\hline & $343-338$ & 349 & 1.464 & $1.049 \mathrm{E}-19$ \\
\hline & $348-343$ & 353 & 1.891 & $1.150 \mathrm{E}-25$ \\
\hline \multirow{7}{*}{$2 \% \mathrm{PVVH} / \mathrm{ZnO}$} & $313-308$ & 329 & 1.276 & $4.123 \mathrm{E}-18$ \\
\hline & $318-313$ & 331 & 1.046 & $2.109 \mathrm{E}-14$ \\
\hline & $323-318$ & 335 & 0.886 & $1.028 \mathrm{E}-11$ \\
\hline & $328-323$ & 337 & 1.639 & $3.685 \mathrm{E}-23$ \\
\hline & $333-328$ & 343 & 1.249 & $7.214 \mathrm{E}-17$ \\
\hline & $338-333$ & 345 & 0.856 & $7.417 \mathrm{E}-11$ \\
\hline & $343-338$ & 347 & 2.750 & $8.788 \mathrm{E}-39$ \\
\hline
\end{tabular}


TS spectrum can be used to study the compensation phenomena which is the linear relationship between the activation energy and $\ln \left(\tau_{\mathrm{o}}\right)$ [17]. The thermodynamic parameters such as the activation enthalpy $\Delta \mathrm{H}$, the activation entropy $\Delta S$, and Gibb's free energy $\Delta \mathrm{G}$ can be calculated by Eyring theory [9]. According to Eyring rate theory, the relaxation time $\tau$ (T) can be expressed in terms of entropy $(\Delta \mathrm{S})$, then $(2)$ becomes

$$
\tau(\mathrm{T})=(\mathrm{h} / \mathrm{kT}) \exp (\Delta \mathrm{G} / \mathrm{kT})
$$

Where $\Delta \mathrm{G}$ is given by

$$
\begin{gathered}
\Delta \mathrm{G}=\Delta \mathrm{H}-\mathrm{T} \Delta \mathrm{S} \\
\operatorname{Ln}(\tau \mathrm{Tk} / \mathrm{h})=\Delta \mathrm{H} / \mathrm{kT}-\Delta \mathrm{S} / \mathrm{k}
\end{gathered}
$$

From (5), $\Delta \mathrm{H}$ could be calculated from the slope of plot $\ln$ $(\tau \mathrm{Tk} / \mathrm{h})$ versus $1000 / \mathrm{T}$ and $\Delta \mathrm{S}$ from the intercept of the line.
The variation of $\ln (\tau \mathrm{Tk} / \mathrm{h})$ against $1 / \mathrm{T}$ for pure PVVH and $\mathrm{PVVH} / \mathrm{ZnO}$ nanocomposites with different concentrations are shown in figure 3 . The figure confirms linear relationship and the extrapolated lines are collected at three different compensation points. At the compensation point, all the discrete processes that constitute the broad relaxation near the glass transition temperature have the same relaxation time. The present of three different compensation points may be attributed to that PVVH is terpolymer incompatible and originated from specific inter- and intra-molecular interaction [18]. $\Delta \mathrm{G}$ was calculated using (4) and considered the temperature $\mathrm{T}=\mathrm{T}_{\mathrm{p}}$. The thermodynamic parameters of all samples are estimated and listed in table 3 . The positive values of $\Delta \mathrm{S}$, imply that the macromolecules are in a more disorder state. In addition, the positive value of $\Delta \mathrm{G}$ means that this system is thermodynamically unstable [19].
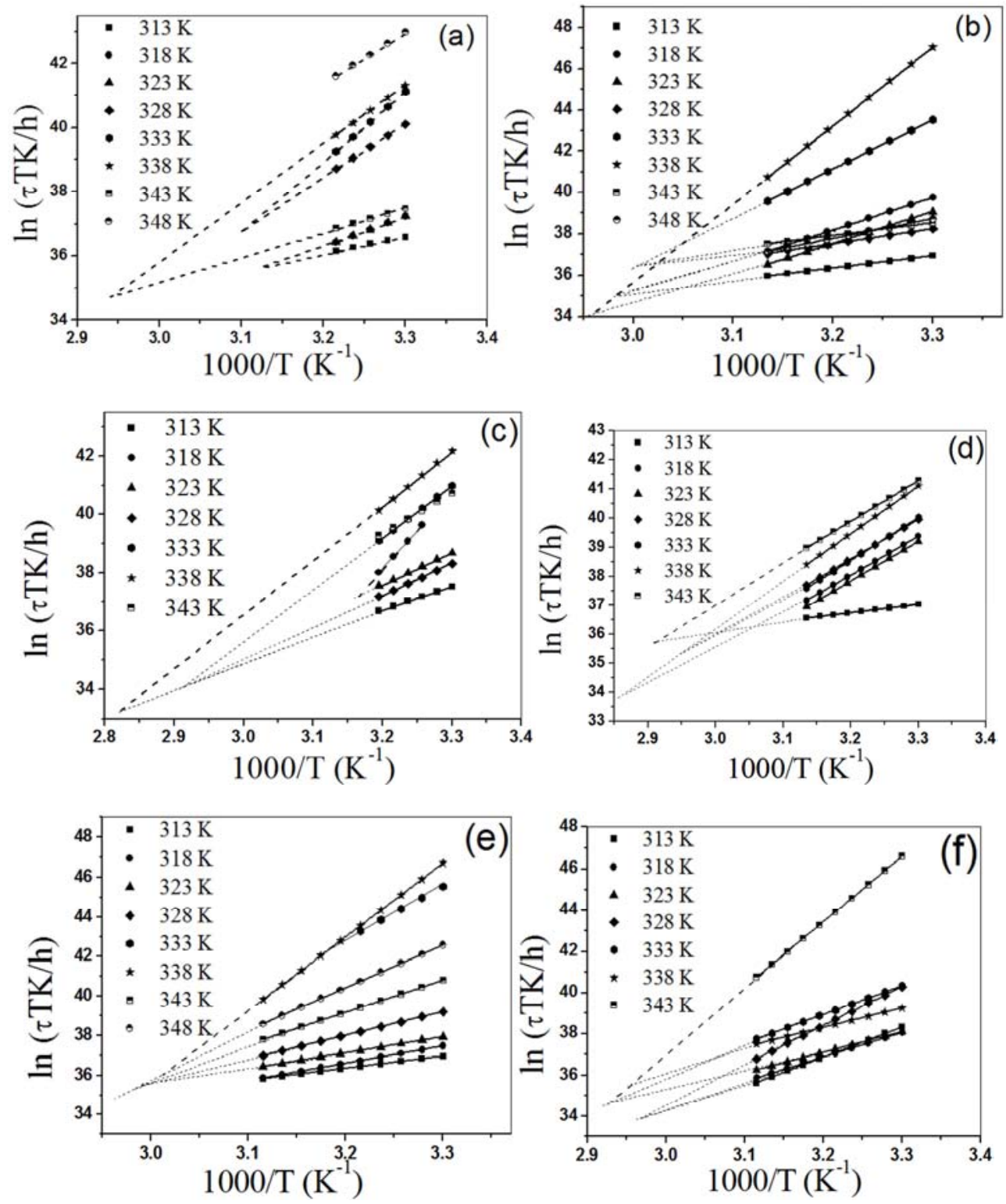

Figure 3. Relation between In $(\tau T k / h)$ versus 1000/T for (a) pure PVVH and PVVH/ZnO nanocomposites with different ZnO nanoparticle concentrations (b: $0.25 \%, c: 0.5 \%, d: 1 \%, e: 1.5 \%$ and $f: 2 \%$ ). 
Table 3. Kinetic parameters calculated at polarization temperature $T_{p}$ for each sample.

\begin{tabular}{|c|c|c|c|c|}
\hline Sample & Poling temperature (K) & Activation enthalpy (eV) & Activation entropy $\left(\mathrm{eVK}^{-1}\right)$ & Gibb's free energy $(\mathrm{eV})$ \\
\hline \multirow{8}{*}{ Pure PVVH } & 313 & 0.430 & -1.733 & 542.932 \\
\hline & 318 & 0.819 & -0.506 & 161.573 \\
\hline & 323 & 0.819 & -0.506 & 164.100 \\
\hline & 328 & 1.414 & 1.212 & -396.036 \\
\hline & 333 & 1.896 & 2.715 & -902.312 \\
\hline & 338 & 1.578 & 1.648 & -555.398 \\
\hline & 343 & 0.625 & -1.168 & 401.152 \\
\hline & 348 & 1.385 & 0.867 & -300.373 \\
\hline \multirow{8}{*}{$0.25 \% \mathrm{PVVH} / \mathrm{ZnO}$} & 313 & 0.507 & -1.511 & 473.410 \\
\hline & 318 & 1.318 & 0.933 & -295.469 \\
\hline & 323 & 1.337 & 1.041 & -334.802 \\
\hline & 328 & 0.603 & -1.303 & 427.901 \\
\hline & 333 & 2.042 & 2.990 & -993.478 \\
\hline & 338 & 3.288 & 6.798 & -2294.334 \\
\hline & 343 & 0.519 & -1.607 & 551.840 \\
\hline & 348 & 0.711 & -0.961 & 335.238 \\
\hline \multirow{7}{*}{$0.5 \% \mathrm{PVVH} / \mathrm{ZnO}$} & 313 & 0.682 & -0.984 & 308.546 \\
\hline & 318 & 2.246 & 3.901 & -1238.203 \\
\hline & 323 & 0.922 & -0.289 & 94.270 \\
\hline & 328 & 0.942 & -0.193 & 64.294 \\
\hline & 333 & 1.530 & 1.519 & -504.198 \\
\hline & 338 & 1.668 & 1.870 & -630.368 \\
\hline & 343 & 1.177 & 0.375 & -127.315 \\
\hline \multirow{7}{*}{$1 \% \mathrm{PVVH} / \mathrm{ZnO}$} & 313 & 0.244 & -2.385 & 746.643 \\
\hline & 318 & 1.148 & 0.395 & -124.419 \\
\hline & 323 & 1.144 & 0.406 & -129.922 \\
\hline & 328 & 1.171 & 0.421 & -136.815 \\
\hline & 333 & 1.231 & 0.622 & -205.941 \\
\hline & 338 & 1.367 & 0.981 & -330.165 \\
\hline & 343 & 1.196 & 0.390 & -132.411 \\
\hline \multirow{8}{*}{$1.5 \% \mathrm{PVVH} / \mathrm{ZnO}$} & 313 & 0.518 & -1.474 & 461.909 \\
\hline & 318 & 0.744 & -0.774 & 246.824 \\
\hline & 323 & 0.709 & -0.934 & 302.362 \\
\hline & 328 & 1.048 & 0.074 & -23.211 \\
\hline & 333 & 2.397 & 3.953 & -1313.902 \\
\hline & 338 & 3.087 & 6.198 & -2091.696 \\
\hline & 343 & 1.435 & 1.207 & -412.613 \\
\hline & 348 & 1.862 & 2.475 & -859.275 \\
\hline \multirow{7}{*}{ 2\% PVVH/ZnO } & 313 & 1.247 & 0.814 & -253.671 \\
\hline & 318 & 1.017 & 0.079 & -23.946 \\
\hline & 323 & 0.857 & -0.455 & 147.752 \\
\hline & 328 & 1.610 & 1.846 & -603.966 \\
\hline & 333 & 1.220 & 0.546 & -180.495 \\
\hline & 338 & 0.827 & -0.656 & 222.404 \\
\hline & 343 & 2.721 & 4.963 & -1699.579 \\
\hline
\end{tabular}

The activation enthalpy and activation free energy have been plotted against polarization temperature for different nanocomposite concentrations, are shown in figure 4 and 5. It shows that both $\Delta \mathrm{G}$ and $\Delta \mathrm{H}$ depend on $\mathrm{T}_{\mathrm{p}}$. It is clear that, in the explored temperature range, the distribution of the activation energy can be attributed to the different relaxation modes in polymeric materials [16]. Table 4 presents the compensation parameters, such as compensation temperature and the compensation relaxation time for all samples. The compensation effect is described in terms of the activation enthalpy-entropy relationship, where the variation in the activation enthalpy is compensated with the variation in the activation energy. 

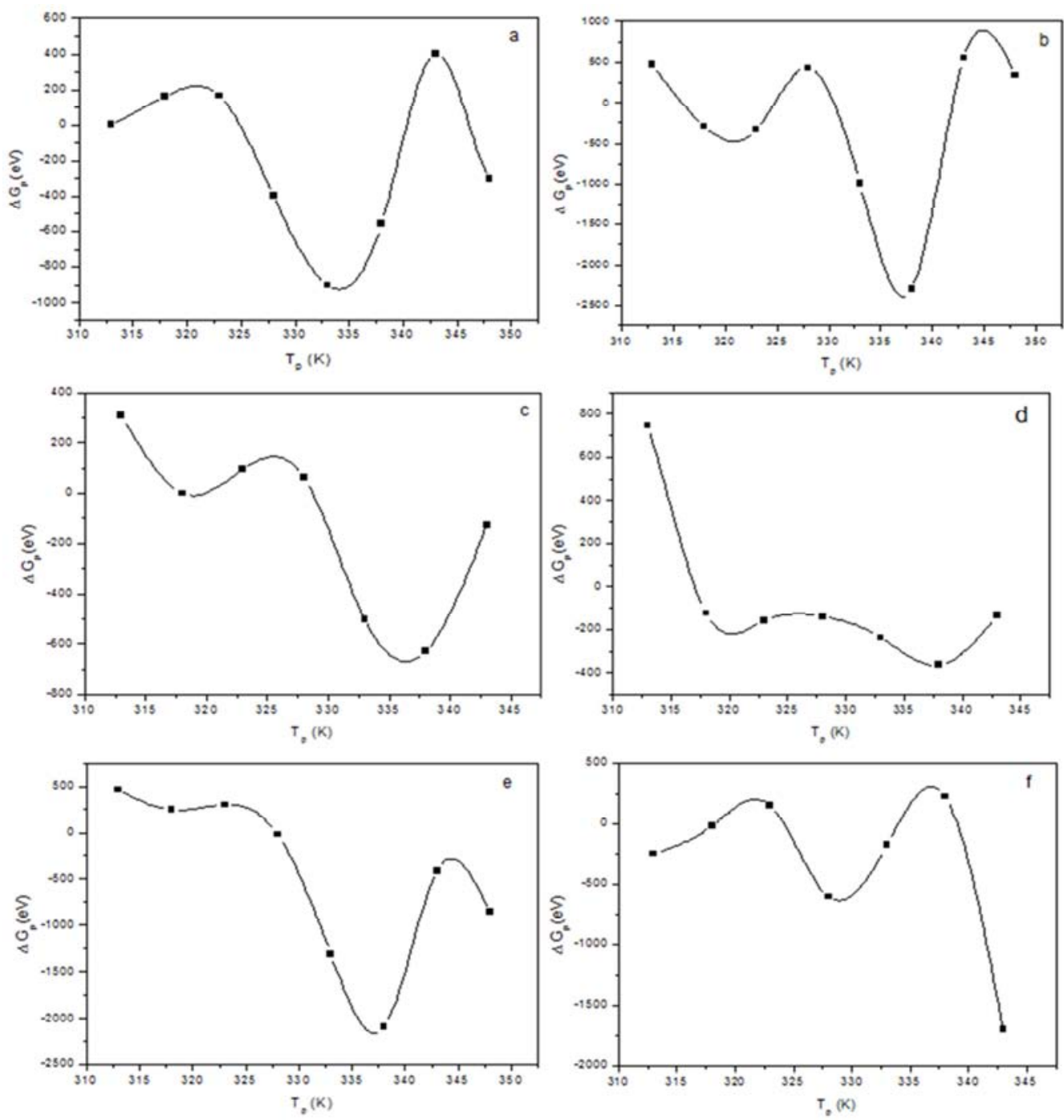

Figure 4. Dependence of Gibb's free energy $\triangle G$ on the polarization temperature $T_{p}$ for (a) pure PVVH and PVVH/ZnO nanocomposites with different ZnO nanoparticle concentrations (b: $0.25 \%, c: 0.5 \%, d: 1 \%, e: 1.5 \%$ and $f: 2 \%$ ).

Table 4. Presents the compensation parameters, the degree of disorder DOD, thermal volume expansion $\beta$ and thermal expansion coefficient $\triangle \beta$.

\begin{tabular}{|c|c|c|c|c|c|}
\hline Sample & $\begin{array}{l}\begin{array}{l}\text { Compensation } \\
\text { temperature (K) }\end{array} \\
\end{array}$ & $\begin{array}{l}\text { Compensation } \\
\text { relaxation time (sec) }\end{array}$ & $\begin{array}{l}\text { Degree of disorder } \\
\left(\text { Cal deg }^{-1}\right)\end{array}$ & $\begin{array}{l}\text { Thermal volume } \\
\text { expansion }\left(\mathrm{K}^{-1}\right)\end{array}$ & $\begin{array}{l}\text { Thermal expansion } \\
\text { coefficient }\left(\mathbf{K}^{-1}\right)\end{array}$ \\
\hline \multirow{3}{*}{ Pure PVVH } & 320.97 & 1922.87 & 25.75 & 0.000779 & 0.000346 \\
\hline & 360.06 & 41.45 & 33.20 & 0.000694 & 0.000309 \\
\hline & 362.66 & 14.83 & 35.24 & 0.000689 & 0.000306 \\
\hline \multirow{3}{*}{$0.25 \% \mathrm{PVVH} / \mathrm{ZnO}$} & 332.57 & 994.03 & 27.00 & 0.000752 & 0.000334 \\
\hline & 335.02 & 233.46 & 29.89 & 0.000746 & 0.000332 \\
\hline & 337.95 & 95.89 & 31.65 & 0.00074 & 0.000329 \\
\hline \multirow{3}{*}{$0.5 \% \mathrm{PVVH} / \mathrm{ZnO}$} & 315.76 & 2310.08 & 25.42 & 0.000792 & 0.000352 \\
\hline & 343.64 & 90.23 & 31.74 & 0.000728 & 0.000323 \\
\hline & 354.61 & 36.49 & 33.48 & 0.000705 & 0.000313 \\
\hline \multirow{3}{*}{$1 \% \mathrm{PVVH} / \mathrm{ZnO}$} & 338.98 & 319.18 & 29.24 & 0.000738 & 0.000328 \\
\hline & 343.16 & 477.09 & 28.41 & 0.000729 & 0.000324 \\
\hline & 349.14 & 72.02 & 32.16 & 0.000716 & 0.000318 \\
\hline \multirow{3}{*}{$1.5 \% \mathrm{PVVH} / \mathrm{ZnO}$} & 313.66 & 425793.98 & 15.00 & 0.000797 & 0.000354 \\
\hline & 320.65 & 592.10 & 28.11 & 0.00078 & 0.000347 \\
\hline & 334.22 & 393.55 & 28.85 & 0.000748 & 0.000332 \\
\hline \multirow{3}{*}{$2 \% \mathrm{PVVH} / \mathrm{ZnO}$} & 337.86 & 56.80 & 32.70 & 0.00074 & 0.000329 \\
\hline & 338.58 & 376.32 & 28.91 & 0.000738 & 0.000328 \\
\hline & 340.97 & 157.88 & 30.63 & 0.000733 & 0.000326 \\
\hline
\end{tabular}



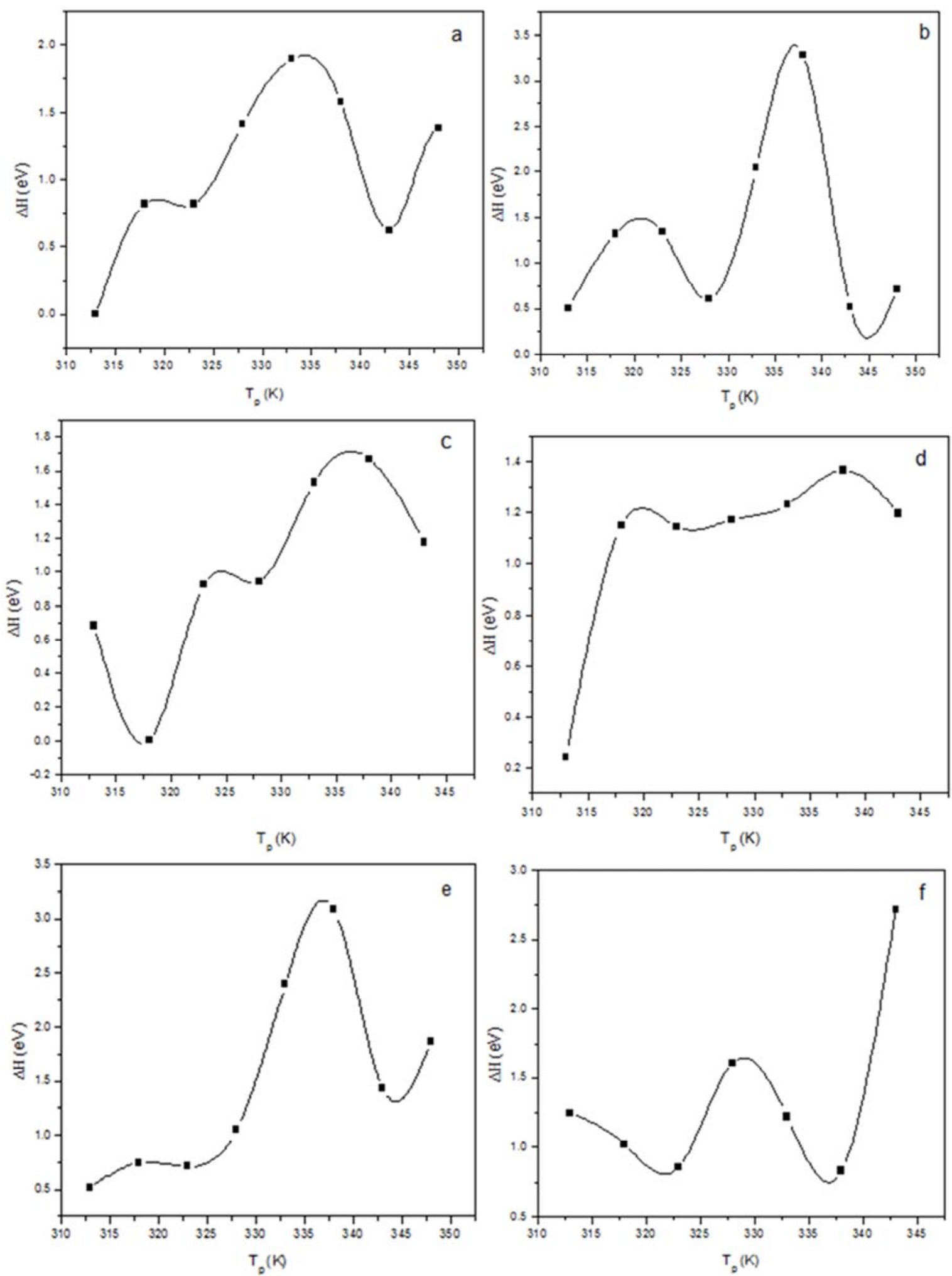

Figure 5. Dependence of enthalpy $\triangle H$ on the polarization temperature $T_{p}$ for (a) pure $P V V H$ and $P V V H / Z n O$ nanocomposites with different $Z n O$ nanoparticle concentrations (b: $0.25 \%, c: 0.5 \%, d: 1 \%, e: 1.5 \%$ and $f: 2 \%$ ).

Figure 6, represented the variation of enthalpy $\Delta \mathrm{H}$ against entropy $\Delta \mathrm{S}$ of $\mathrm{PVVH} / \mathrm{ZnO}$ nanocomposite with different concentrations. A linear relationship has been observed for all samples which is a consequence of the structure changes towards equilibrium with increasing the temperature [15].
The energy of the blend relaxation process comprises not only the energy required to displace the segments along the reaction path, but also the energy required to create these segments, which confirms the validity of the compensation law [20]. 

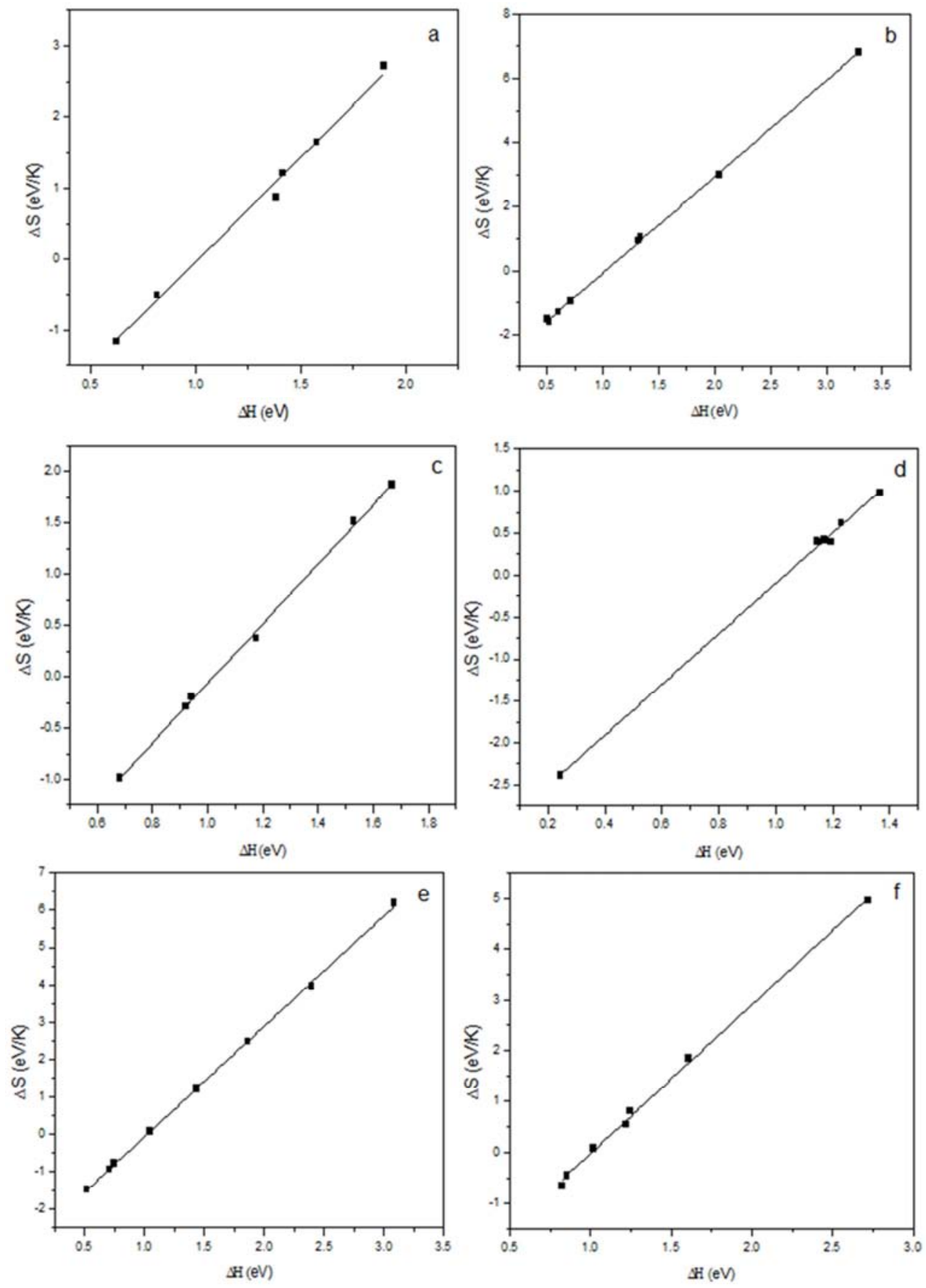

Figure 6. Activated states entropy $\triangle S$ plotted versus enthalpy $\triangle H$ of (a) pure PVVH and PVVH/ZnO nanocomposites with different ZnO nanoparticle concentrations (b: $0.25 \%, c: 0.5 \%, d: 1 \%, e: 1.5 \%$ and $f: 2 \%$ ).

The density of disorder DOD reflects the degree of compatibility of copolymers [15] and can be defined by the relation of entropy against enthalpy when $T_{p}$ is varied. DOD can be calculated using the coordinating points $\mathrm{T}_{\mathrm{c}}$ and $\tau_{\mathrm{c}}$ from the equation [21].

$$
\mathrm{DOD}=100-2\left[\ln \left(\mathrm{T}_{\mathrm{c}} \tau_{\mathrm{c}}\right)+23.76\right]
$$

The number 100 is arbitrarily added to shift all the values to the positive side. The DOD can be used to measure the degree of disordered and ranged in all investigated samples from 15 to 35.24 shown in table 4. For amorphous materials, DOD values vary from 30 to 70 [21].

The relation between $\Delta \mathrm{S}$ and $\Delta \mathrm{H}$ could be correlated to the coefficient of thermal volume expansion $\beta$ for the polymer fluid using the empirical relationship [15].

$$
\Delta \mathrm{S}=\mathrm{M}_{\mathrm{c}} \beta \Delta \mathrm{H}
$$

Where $M_{c}$ is dimensionless constant and its value is 4 . Then, the compensation temperature can be defined as

$$
\mathrm{T}_{\mathrm{c}}=1 / \beta \mathrm{M}_{\mathrm{c}}
$$


The differences in the values of the thermal expansion coefficient $\Delta \beta$ above and below $\mathrm{T}_{\mathrm{g}}$ can be determined from the formula $\Delta \beta=1 / 9 \mathrm{~T}_{\mathrm{c}}$ for all samples. Values of $\beta$ and $\Delta \beta$ are calculated and shown in table 4.

\section{Conclusions}

TSDC global spectra of pure PVVH and PVVH/ZnO nanocomposites exhibit a single relaxation process, with a peak at a maximum temperature near to the glass transition of each concentration. The magnitude of current and its peak position increases with the concentration. Each global spectrum has been resolved into elementary processes characterized by a set of single relaxation peaks. The relaxations can be described by the distribution of relaxation times with different activation energies in each sample. The compensation phenomena revealed the presence of three compensation points and a linear relation between enthalpy and entropy. Also, the degree of disorder and the coefficient of thermal volume expansions were calculated.

\section{References}

[1] Barkade, Shrikant S., Jitendra B. Naik, and Shirish H. Sonawane. "Ultrasound assisted miniemulsion synthesis of polyaniline/Ag nanocomposite and its application for ethanol vapor sensing." Colloids and Surfaces A: Physicochemical and Engineering Aspects 378.1 (2011): 94-98.

[2] Zhang, J., et al., Microwave dielectric properties and thermally stimulated depolarization currents of $(1-\mathrm{x})$ $\mathrm{MgTiO}_{3}-\mathrm{xCa} 0.8 \mathrm{Sr} 0.2 \mathrm{TiO}_{3}$ ceramics. Journal of the American Ceramic Society, 2015. 98(5): p. 1548-1554.

[3] Zhang, P., et al. Thermally stimulated depolarization processes in zirconia toughened alumina ceramics. in Dielectrics (ICD), 2016 IEEE International Conference on. 2016. IEEE.

[4] Ko, Y. S., et al. Temperature dependent impedance spectroscopy and Thermally Stimulated Depolarization Current (TSDC) analysis of disperse red 1-co-poly (methyl methacrylate) copolymers. in SPIE Smart Structures and Materials + Nondestructive Evaluation and Health Monitoring. 2016. International Society for Optics and Photonics.

[5] Ahmed M. T. "Thermally Stimulated Discharge Current and Thermal Sampling Studies on Poly (Vinyl Chloride- CoVinylacetate-Co-2-Hydroxypropyl Acrylate)/Poly (Methyl Methacrylate) Blends." International Journal of Material Science ISSN 0973-4589 Volume 4, Number 1 (2009), pp. $57-71$.

[6] Ruckenstein Eli, and Yumin Yuan. "Nanocomposites of rigid polyamide dispersed in flexible vinyl polymer." Polymer 38.15 (1997): 3855-3860.

[7] Joao F. Mano. "The relaxation frequency as observed in thermally stimulated depolarisation current experiments in polymers." Thermochimica Acta 332 (1999) 161-170.

[8] Ragab H. S., Shehab A., Attia G. and Abd El- Kader F. H.
"Effect of the metal oxides additives on the electrical properties of $\beta$-eucryptite ceramics." Egypt. J. Sol. 26 (2003).

[9] Jung-Fong Lin, Ching-Fu Ho, Shin-Yon Wu and Steve K. Huang. "Study on the depolarization transition of the modified epoxy resins containing penta-coordinated aromatic phosphate by thermally stimulated current technique with the relaxation mapping analysis." Thermochimica Acta 333 (1999) 55-65.

[10] Sauer Bryan B., and Joaquim J. Moura Ramos. "Comments on compensation analysis as applied to thermally stimulated current thermal sampling." Polymer 38. 16 (1997): 4065-4069.

[11] Dargent, E., Kattan M., Cabot C., Lebaudy P., Ledru J. and Grenet J. "Compensation effect observed in thermally stimulated depolarization currents analysis of polymers." Journal of applied polymer science 74. 11 (1999): 2716-2723.

[12] Fragiadakis, Daniel, Polycarpos Pissis, and Liliane Bokobza. "Glass transition and molecular dynamics in poly (dimethylsiloxane)/silica nanocomposites." Polymer 46.16 (2005): 6001-6008

[13] Elashmawi, I. S., Hakeem N. A., Marei L. K. and Hanna F. F. "Structure and performance of $\mathrm{ZnO} / \mathrm{PVC}$ nanocomposites." Physica B: Condensed Matter 405.19 (2010): 4163-4169.

[14] Migahed M. D., Ahmed M. T., Kotp A. E. and El-Henawy M. I. "Iterative evaluation of thermally stimulated depolarization current peak parameters in polymers: A dipolar interaction approach to molecular dipole relaxation" Journal of applied physics. Vol. 78 (1995) pp. 5079.

[15] Ahmed M. T. and Fahmy T. Alpha relaxation study in poly(vinyl chloride)/poly(ethyl methacrylate) blends using thermally stimulated currents, Polymer International 49 (7) (2000) $669-677$.

[16] Ahmed M. T. and Fahmy T. Study of the Relaxation Phenomenon of Poly(vinyl chloride-co-vinylacetate-co-2hydroxypropyl acrylate)/ Poly(methyl methacrylate) Blends Using TSDC-TS Technique: Dipole-dipole Interaction ApproachJournal of the Korean Physical Society, Vol. 59, No. 1, July (2011), pp. 98_104.

[17] Ahmed M. T. and Fahmy T. Depolarization current characterization of poly (vinyl chloride-co-vinyl acetate-co-22 hydroxypropyl acrylate) polymer films: thermal sampling study, $7^{\text {th }}$ Arab International conference on polymer science \& technology Egypt, October (2003) 5-9.

[18] Ahmed M. T. and Fahmy T. "Distributed relaxations in PVC/PEMA polymer blends as revealed by thermostimulated depolarization current." Polymer testing 18 (1999) 589-599.

[19] Values S. G. and Tager A. physical chemistry of polymer, Mir publishers Moscow (1978).

[20] Migahed M. D., Ahmed M. T. and Kotp A. E. "Thermoskinetic characteristic study of alfa-relaxation in poly (methyl methacrylate) poly (vinyl chloride) blend" journal of polymer materials 19 (2001) 157-164.

[21] Ibar J. P. Application of compensation phenomena to the thermal analysis characterization of polymers: Introducing the degree of disorder (DOD) number, polymer engineering \& science. Volume 31, Issue 20 October (1991) Pages 14671475 . 